\title{
Renal cortical hypoperfusion caused by glyphosate-surfactant herbicide
}

\author{
Takashin Nakayama $^{1}$ (D) Yu Mimura ${ }^{2} \cdot$ Keita Hirano $^{1}$
}

Received: 28 November 2018 / Accepted: 3 January 2019 / Published online: 19 January 2019

(c) The Author(s) 2019

Keywords Renal cortical necrosis · Reverse rim sign · Glyphosate-surfactant herbicide

A 70-year-old woman presented with abdominal pain $2 \mathrm{~h}$ after ingesting $500 \mathrm{ml}$ of glyphosate-surfactant herbicide (GPSH). As her abdominal pain worsened, contrastenhanced computed tomography was performed $12 \mathrm{~h}$ after the admission, demonstrating renal blood flow shunting through the medulla which is called "reverse rim sign" (Fig. 1). She had been anuric since hospitalization with sufficient mean artery pressure and negative blood culture. Despite intensive care, she died of multiple organ failure on the 6th day of hospitalization.

Following ingestion of GPSH known for mitochondrial toxicity, our patient developed acute kidney injury (AKI) with diffuse renal cortical hypoperfusion [1]. We assumed that her AKI was attributed to vasoconstriction of small intracortical blood vessels, intravascular thrombosis or mitochondrial toxicity of GSPH resulting in disorders of the mitochondrion-rich renal cortical region [2]. Considering that the lesion was homogeneously localized to the renal cortex, the latter assumption seems to be unignorable.

Takashin Nakayama

takashin.nakayama@gmail.com

1 Department of Internal Medicine, Ashikaga Red Cross Hospital, Tochigi, 284-1 Yobe, Ashikaga, Tochigi 326-0843, Japan

2 Department of Psychiatry, Ashikaga Red Cross Hospital, Tochigi, 284-1 Yobe, Ashikaga, Tochigi 326-0843, Japan

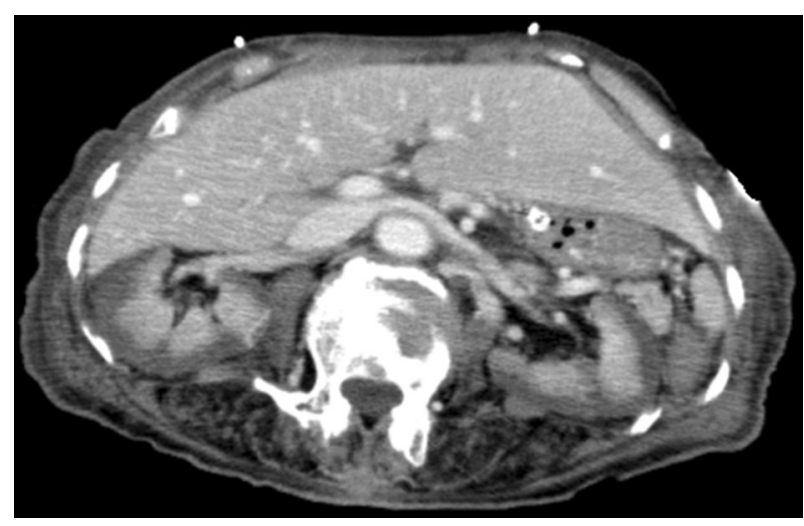

Fig. 1 Contrast-enhanced computed tomography in the axial view demonstrating a non-enhancing renal cortex against a background of intact medullary perfusion

\section{Compliance with ethical standards}

Conflict of interest The authors have declared that no conflicts of interest exist.

Ethical approval This article does not involve research using human participants or animals.

Informed consent Written informed consent was obtained from the patient's family because the patient was incapable.

Open Access This article is distributed under the terms of the Creative Commons Attribution 4.0 International License (http://creativeco mmons.org/licenses/by/4.0/), which permits unrestricted use, distribution, and reproduction in any medium, provided you give appropriate credit to the original author(s) and the source, provide a link to the Creative Commons license, and indicate if changes were made. 


\section{References}

Publisher's Note Springer Nature remains neutral with regard to jurisdictional claims in published maps and institutional affiliations.

1. Bradberry SM, Proudfoot AT, Vale JA. Glyphosate poisoning. Toxicol Rev. 2004;23:159-67.

2. Kim HJ, Cho OK. CT scan as an important diagnostic tool in the initial phase of diffuse bilateral renal cortical necrosis. Clin Nephrol. 1996;45:125-30. 